\title{
Detection of central-to-radial arterial pressure gradient (CRPG) after cardiac surgery with cardiopulmonary bypass
}

\section{Guigue L. ${ }^{1,2}$, Anglade D. ${ }^{1,3}$, Smal N. ${ }^{4}$, Lavault Y², Lavault C. ${ }^{2}$, Fellahi J.L. ${ }^{4}$,}

${ }^{1}$ TIMC-IMAG Laboratory, Grenoble, ${ }^{2}$ All Biomedical, Grenoble, ${ }^{3}$ Anesthesiology and intensive care unit, Alpes University Hospital, Grenoble, ${ }^{4}$ Anesthesiology and Critical Care, Hôpital Cardiologique Louis Pradel, Lyon (France)

Background: Cardiac surgery with cardiopulmonary bypass (CPB) is responsible for CRPG in nearly 30 to $45 \%$ of patient [1]. The current study aimed at identifying the occurrence of CRPG by using the pulse wave analysis of radial arterial pressure signal.

Methods: After approval by IRB, 39 adult patients undergoing elective cardiac surgery with an expected CPB duration of at least 90 min were prospectively included in the study. Arterial pressure by means of a radial artery catheter and ECG were recorded in all patients. A sub-group of 12 patients was selected on a clinical basis for an additional direct measurement of intraoperative aortic pressure.
All data were registered and digitized. Pulse wave analysis of radial arterial pressure recordings included calculation of pulse wave velocity and the variability of the amplitude spectrum of the first harmonic (Figure 1 and 2). We looked for a correlation between CRPG and pulse wave analysis by using statistical analysis of variance (ANOVA, $p<0.05$ ).

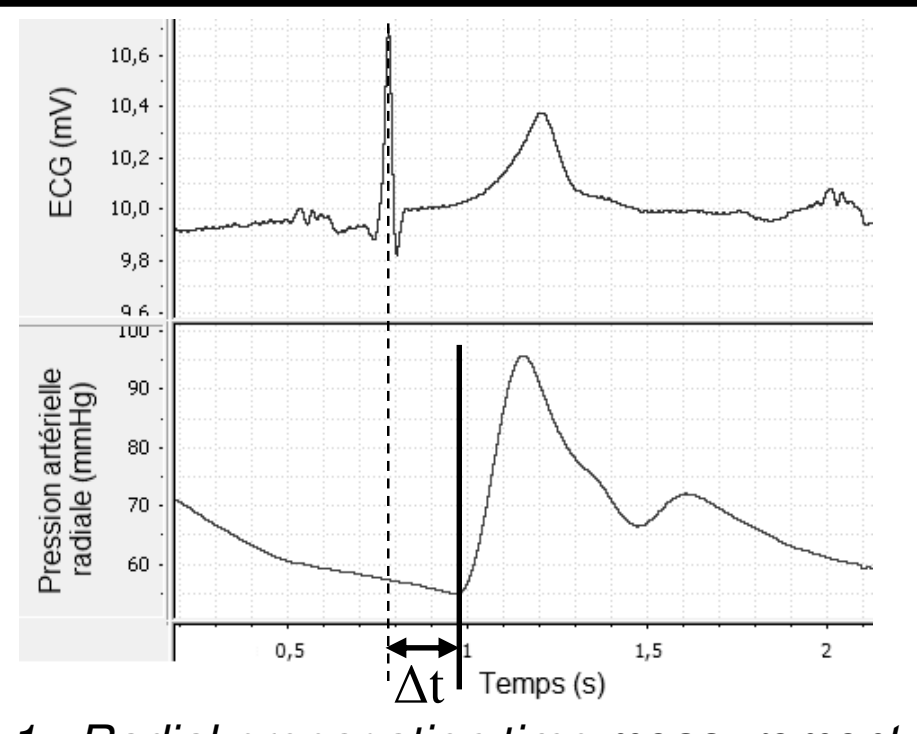

Figure 1: Radial propagation time measurement $(\Delta t)$

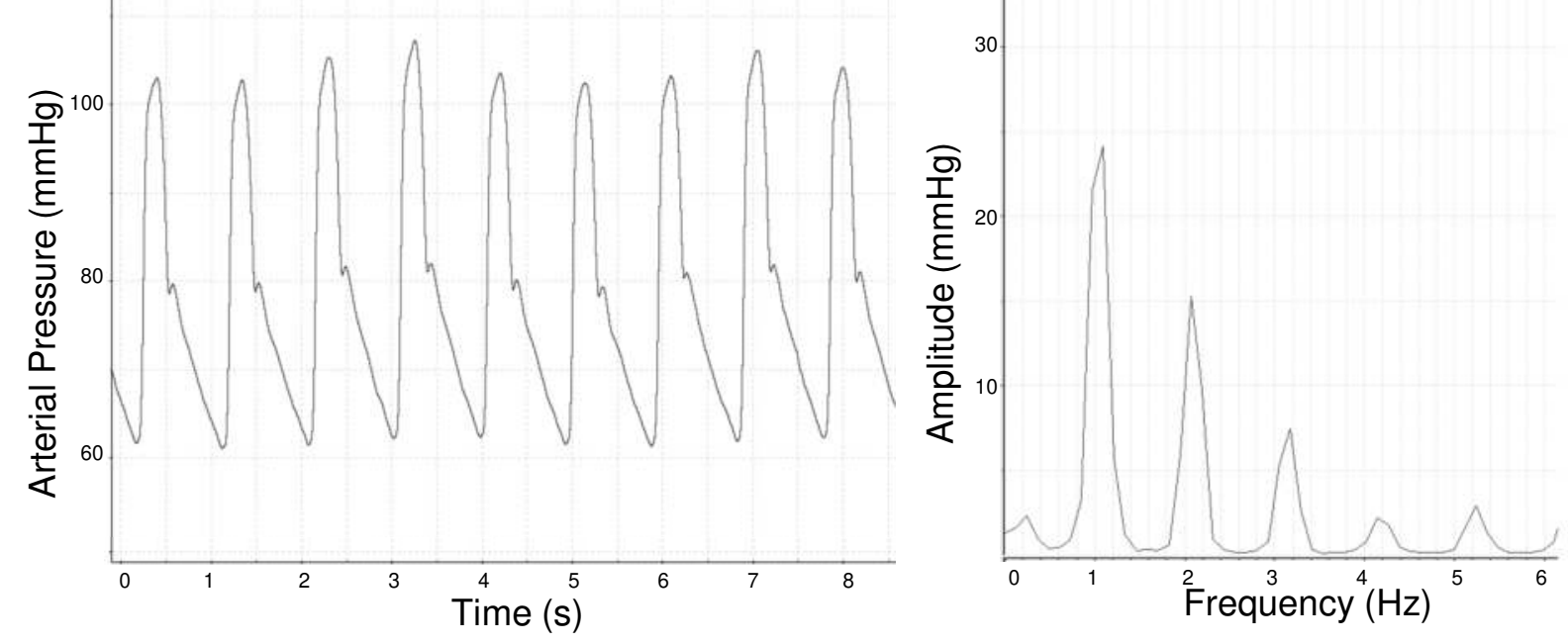

Figure 2: Amplitude spectrum of arterial pulse wave harmonic analysis

Results: In the sub-group of 12 patients with direct aortic pressure measurement, 6 patients presented a systolic CRPG greater than $10 \mathrm{mmHg}(\Delta \mathrm{P})$. In this sub-group, both radial propagation time $(218.8 \pm 35.5 \mathrm{~ms} v \mathrm{~s} .202 .3 \pm 13.3 \mathrm{~ms}, \mathrm{p}=0.047)$ and harmonic analysis variability (3.17 $\pm 0.88 \mathrm{mmHg}$ vs. $1.65 \pm 0.53 \mathrm{mmHg}, \mathrm{p}=0.006)$ were correlated with an elevated CRPG (Figure 3).

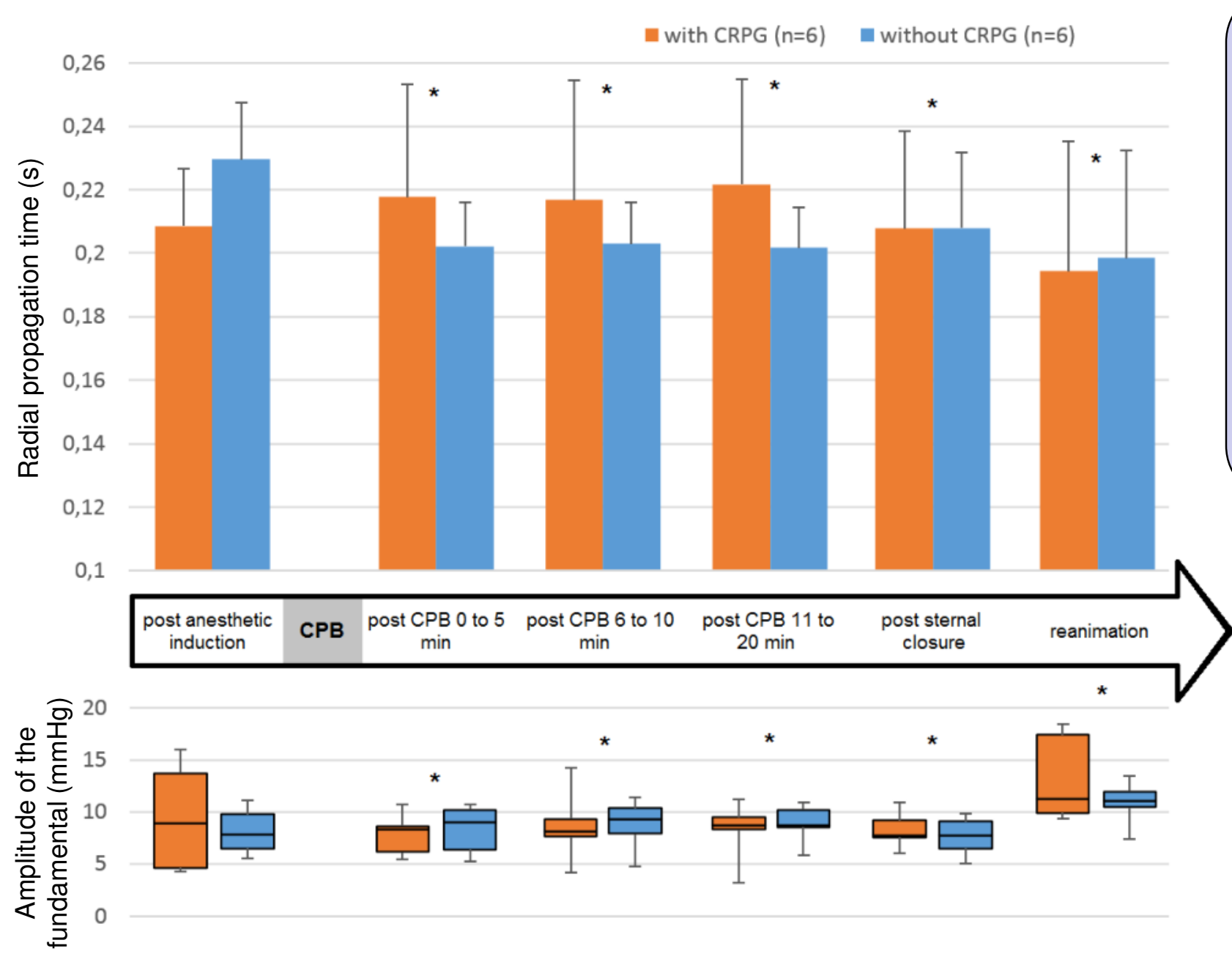

Figure 3 : Evolution of radial propagation time $(M \pm S D)$ and Amplitude of the fundamental (Median \pm max and min) during CPB for the 2 groups " with » or « without » CRPG ( $n=12)$. (ANOVA, a $p$-value $<0.05$ was significant and symbolised by *)
An elevated CRPG could not be adequately predicted by one of these criteria alone, but by the merging of the two criteria. Using this method in the 27 remaining patients without direct measurement of aortic pressure, we were able to identify 15 patients at risk. We observed that Euroscore was significantly higher $(p=0.035)$ in these 15 patients (Table 1$)$.

\begin{tabular}{|c|c|c|c|}
\hline Variables & $\begin{array}{c}\text { Seem to present } \\
\text { a CRPG (n=15) }\end{array}$ & $\begin{array}{c}\text { Seem not to show } \\
\text { a CRPG (n=11) }\end{array}$ & P-value \\
\hline Euroscore & $\begin{array}{c}12,9 \pm 10,0 \\
(2,1 ; 36,2)\end{array}$ & $\begin{array}{c}4,9 \pm 3,9 \\
(1,2 ; 13,5)\end{array}$ & $0,035^{\star}$ \\
\hline $\begin{array}{c}\text { CPB duration } \\
\text { (min) }\end{array}$ & $\begin{array}{c}117,9 \pm 41,0 \\
(59 ; 219)\end{array}$ & $\begin{array}{c}98,7 \pm 21,7 \\
(57 ; 128)\end{array}$ & 0,122 \\
\hline $\begin{array}{c}\text { Medicament } \\
\text { vasoactive }\end{array}$ & $73 \% \pm 46 \%$ & $82 \% \pm 41 \%$ & 0,599 \\
\hline
\end{tabular}

Table 1: Risk factors comparison between patients with presumed CRPG versus patients without presumed CRPG after classification according to the method of detection in the group without gold standard measurements. * by ANOVA. Mean $\pm S D$ (minimum; maximum)

Conclusions: Using calculation of pulse wave velocity in addition to harmonic analysis variability can help to identify patients at risk of elevated CRPG. Such measurements could avoid the use of inappropriate vasopressors and/or inotropic agents in the early postoperative period. 